\title{
The erasure of reinstated fear
}

\author{
ROBERT A. RESCORLA and CHRISTOPHER L. CUNNINGHAM \\ Yale University, New Haven, Connecticut 06520
}

\begin{abstract}
Three experiments investigated the reinstatement of fear to a previously conditioned and extinguished CS as a result of separate presentation of the original US. That reinstatement was found to be sharply attenuated by nonreinforcement of a second fear elicitor between presentations of the US and testing of the CS. This "erasure" of reinstatement depended upon the fear-eliciting power of the intervening stimulus and, under some circumstances, was essentially complete. Moreover, erasure reduced not only the response to the CS but also the extinction it underwent as a result of subsequent nonreinforcement. It is argued that neither the conditioning of background stimuli nor stimulus generalization among explicit CSs provides an adequate account of these reinstatement and erasure results. Rather, they are interpreted in terms of the construction and destruction of a nonassociative representation of the US during conditioning, extinction, reinstatement, and erasure. In that context, some inferences can be made about the rules governing these nonassociative changes and the ways in which they interact with modifications in associations.
\end{abstract}

Recently, Rescorla and Heth (1975) reported a postextinction phenomenon which they labeled as "reinstatement" of fear. They found that much of the decremental effect resulting from the nonreinforced presentation of a previously reinforced conditioned stimulus (CS) could be reversed simply by presentation of the original shock reinforcer. Moreover, their experiments provided evidence that this reinstatement could not easily be attributed to the reinstitution of the stimulus conditions of original training, the training of background stimuli, or stimulus generalization. Instead they offered an interpretation in terms of the changes which might take place in the organism's representation of the reinforcer itself during the course of extinction.

Employing a general description of conditioning which has proven useful in other contexts, Rescorla and Heth argued that during acquisition the organism not only forms associations but also constructs representations of the events to be associated. Other evidence (e.g., Holland \& Rescorla, 1975; Rescorla, 1974) has suggested that the production of a conditioned response depends upon the integrity of both these kinds of learning; modification of either the association or the reinforcer representation can result in changes in the level of responding produced by a CS. Furthermore, Rescorla and Heth suggested that parallel changes can take place during the exinction.

This research was supported by National Science Foundation Grant GB-28703X. Thanks are due to Peter C. Holland and Joan Bombace for assistance in running the animals. Reprint requests should be sent to Robert A. Rescorla, Department of Psychology, Yale University, 2 Hillhouse Avenue, New Haven Connecticut 06520. C. L. Cunningham is a postdoctoral fellow, National Institute of Mental Health (1 F32 MH-05106-01).
Nonreinforced presentations of the CS might not only modify associative connections; they might also produce deterioration in the representation of the unconditioned stimulus (US). They argued that activation of that representation in the absence of the US itself might be sufficient to depress the representation. If so, then subsequent presentation of the US could be viewed as reversing that depression and permitting any associative strength remaining to a $\mathrm{CS}$ to be evident in the form of a reinstated conditioned response.

The present report is a further investigation of this reinstatement phenomenon, directed particularly at a manipulation with potential to attenuate its magnitude. As such, the experiments reported here constitute an initial investigation of a procedure which might reduce a US representation. The starting point for these experiments was the observation that although US-produced reinstatement is substantial in magnitude, it is also relatively short-lived in the sense that additional nonreinforced CS presentations during testing lead to rapid reduction in the response. It is possible, of course, that this reduction arises from rapid associative change; however, the rate of change is substantially greater than that normally observed at comparable levels in the course of original extinction. An equally plausible alternative suggested the manipulation studied here: that nonreinforced test presentations of the CS rapidly reverse the effect of the reinstating US by producing changes in the US representation. In that case, the rapid disappearance of reinstatement during testing might not depend upon the repeated occurrence of that particular CS. Any stimulus associated with the US, if nonreinforced between reinstating shocks 
and testing of the extinguished CS, should be capable of attenuating reinstatement.

The experiments reported here explore this possibility, that intervening presentations of other stimuli might "erase" reinstatement. Experiment 1 was designed to provide an initial demonstration of an erasure effect. Experiment 2 documents the need for erasing stimuli to be fear eliciting. Experiment 3 examined the completeness of erasure and, additionally, used it as a tool for studying the interactions between associative and nonassociative changes during extinction.

\section{EXPERIMENT 1}

This experiment was intended to replicate the earlier findings of reinstatement and to give initial information on the possibility that the presentation of other stimuli could erase that reinstatement. It examined the reinstating effects of two treatments previously reported, shocks signaled by other CSs and unsignaled shocks. In addition, it studied the potential erasing effects of two fear-eliciting stimuli, one of which had itself been subjected to extinction and reinstatement and one of which had been reconditioned.

\section{Method}

Subjects and Apparatus. The subjects were 32 male SpragueDawley rats about 90 days old at the start of the experiment. They were maintained throughout the experiment at $80 \%$ of their initial ad-lib weight.

The apparatus consisted of eight identical Skinner boxes measuring $22.9 \times 20.3 \times 20.3 \mathrm{~cm}$. Each chamber had a recessed food magazine in the center of the end wall and a bar to the left of the magazine. The floor of the chamber was composed of $.48-\mathrm{cm}$ stainless steel rods spaced $1.9 \mathrm{~cm}$ apart. The grid could be electrified through a relay-sequence scrambler from a highvoltage high-resistance shock source. The two end walls of the chamber were aluminum; the side walls and top were clear Plexiglas. Each Skinner box was enclosed in a sound- and light-resistant shell. Mounted on the wall of this shell was a 6-W houselight and a speaker. The speaker permitted the presentation of a $1,800-\mathrm{Hz}$ tone, which measured about $76 \mathrm{~dB}$ re $20 \mu \mathrm{N} / \mathrm{m}^{2}$ against a background level of $62 \mathrm{~dB}$. Experimental events were controlled and recorded automatically by relay equipment located in an adjoining room.

Procedure. In the first session, all rats were magazine trained automatically with food pellets (P. J. Noyes, $45 \mathrm{mg}$ ) delivered on a variable time 1-min schedule. In addition, each barpress yielded a food pellet. This session continued until the animal had emitted about 50 barpresses; shaping was used if necessary. Starting with the second experimental day, all sessions were $2 \mathrm{~h}$ long and all involved food on a variable interval (VI) schedule. For the first 20 min of Day 2, the schedule was VI $1 \mathrm{~min}$; thereafter, it was VI 2 min. Simple VI training continued for five sessions.

During the next session, the stimuli to be used in conditioning were pretested by superimposition on the VI performance. Two 2 -min presentations each of the $1,800-\mathrm{Hz}$ tone and of a $2 / \mathrm{sec}$ flashing of the normally off houselight were given, with a mean intertrial interval of $30 \mathrm{~min}$. The next five sessions established fear conditioning to both the light and the tone. These sessions were identical to the pretest, except that each CS terminated in a .5-sec,
5-mA footshock. On each of the next six sessions, this fear was extinguished by the presentation of two nonreinforced occurrences each of the light and the tone.

After extinction, the animals were divided into four groups of eight each, matched for their extinction performance. All groups received a reinstatement session and then a single test session. The design permitted assessment of the magnitude of reinstatement as a function of whether or not the light signaled the reinstating shocks; it also allowed examination of the erasing effects of test session presentations of a light which had been reconditioned or itself reinstated.

During the 2-h reinstatement session, all animals received four $.5-\mathrm{sec}, .5 \mathrm{~mA}$ shocks, given at a mean intershock interval of $30 \mathrm{~min}$. For two groups $(\mathrm{L}+/ \mathrm{L}$ and $\mathrm{L}+/-)$, each shock was preceded by the 2 -min light, as is indicated by the $\mathrm{L}+$ before the slash in the group designation. For two other groups $(+/ \mathrm{L}$ and $+/-$ ), the shocks were unsignaled.

On the next day, the reinstating effects of those shocks upon the response to the tone were tested in a 2-h session, during which barpressing was reinforced on a VI 2-min schedule. During the second hour of that session, all animals received two nonreinforced presentations of the 2-min tone. For two groups ( $L+/ L$ and $+/ L$ ), two nonreinforced presentations of the light were given during the first hour of that session, as is indicated by the $\mathrm{L}$ after the slash in the group designation. For the other two groups $(L+/-$ and $+/-)$, no stimuli were presented during the first hour of the test session. The data of interest are the amounts of fear controlled by the tone as a function of signaled (Group L $+/-$ ) or unsignaled (Group $+/-$ ) reinstatement and of subsequent erasure by a reconditioned (Group $\mathrm{L}+/ \mathrm{L}$ ) or a reinstated (Group + / L) light.

The measure of conditioning used throughout was the amount of barpressing produced during a tone. In order to attenuate the effects of individual differences in overall rate of responding, the results are plotted in terms of a suppression ratio. This ratio has the form $\mathrm{A} /(\mathrm{A}+\mathrm{B})$, where $\mathrm{A}$ is the rate of responding during the $C S$ and $B$ is the rate of responding in a comparable period prior to CS onset. Thus, a ratio of 0 indicates no responding during the CS (good conditioning), whereas one of 0.5 indicates similar rates of responding during the $\mathrm{CS}$ and pre-CS periods (little conditioning).

\section{Results and Discussion}

The principal results are displayed in Figure 1, which shows the mean suppression ratios for the tone on each of its presentations during the final extinction day and during the test day following reinstatement. As a result of the matching, extinction performance on the two tone trials of Extinction Day 6 was comparable among the four groups.

During the first tone trial of the test session, both groups which had received reinstating shocks without subsequent light presentation (Groups $\mathrm{L}+/-$ and $+/-$ ) showed substantial increases in suppression. As in previous studies, that reinstatement was shortlived, so as to be noticeably reduced on the second test trial. Because earlier studies (see also Experiment 3 below) had indicated that this increase in suppression would not occur in the absence of reinstating shocks, the present study did not contain an explicit comparison with groups not receiving reinstatement. However, comparison of the firsttrial performance on the test day with that on Extinction Day 6 provides what may be viewed as a conservative assessment of the impact of reinstating 
shocks. Both Group $\mathrm{L}+/-$ and Group $+/-$ showed greater suppression after reinstatement (Wilcoxon Ts $=0,1$, ps $<.02$ ).

In contrast, those groups which had nonreinforced light presentations within the test session prior to the tone trials (Groups $L+/ L$ and $+/ L$ ) showed little increase in suppression compared with the terminal extinction level. This suggests that those light presentations erased the effects of reinstatement. A Wilson nonparametric factorial analysis performed on the first tone test trial confirmed the erasing effect of light presentation $\left(\chi_{1}^{2}=4.29, p<\right.$ .05 ), but revealed no reliable effect either of the light signaling the reinstating shock or of an interaction. Individual Mann-Whitney $U$ tests found that within each reinstatement procedure $(\mathrm{L}+$ or +$)$ the nonreinforced light presentations attenuated suppression to the tone (Us $<15$, ps $<.05$ ). On these test trials, the mean number of responses in the 2 -min pre-CS periods for Groups $\mathrm{L}+/-,+/-, \mathrm{L}+/ \mathrm{L}$, and $+/ \mathrm{L}$ were $16,15,12$, and 13 , respectively. Those rates were not reliably different from each other.

During the two light presentations of the test session, Group $\mathrm{L}+/ \mathrm{L}$ showed more suppression than did Group $+/ \mathrm{L}$ (.01 vs. .20). That difference presumably indicates the conditioning accomplished when light precedes the shock on reinstating trials. However, the suggestion in Figure 1 that this greater suppression to the light produced somewhat greater erasure of the reinstatement to the tone was not confirmed statistically.

These results confirm earlier findings that shocks delivered independently of an extinguished CS can reinstate some of the $C R$, whether or not those shocks are signaled by another CS. Furthermore, they suggest that intervening nonreinforced presentation of another fear elicitor can attenuate that effect. These observations agree with the notion that reinstatement is a nonassociative effect, the occurrence and removal of which is relatively free of the occurrence of a particular CS.

\section{EXPERIMENT 2}

This experiment had three purposes. First, it intended to replicate the erasure effect. Second, it investigated the importance of the eraser's having feareliciting power. On the present view, the eraser removes reinstatement only because it arouses the US representation in the absence of the US itself and thus depresses that representation. Consequently, the ability of a stimulus to activate the US representation, as indexed by its ability to produce conditioned fear, should be an important determinant of erasure. The design of Experiment 1 incidentally produced lights which elicited two different levels of fear; but indications that they were differentially effective as

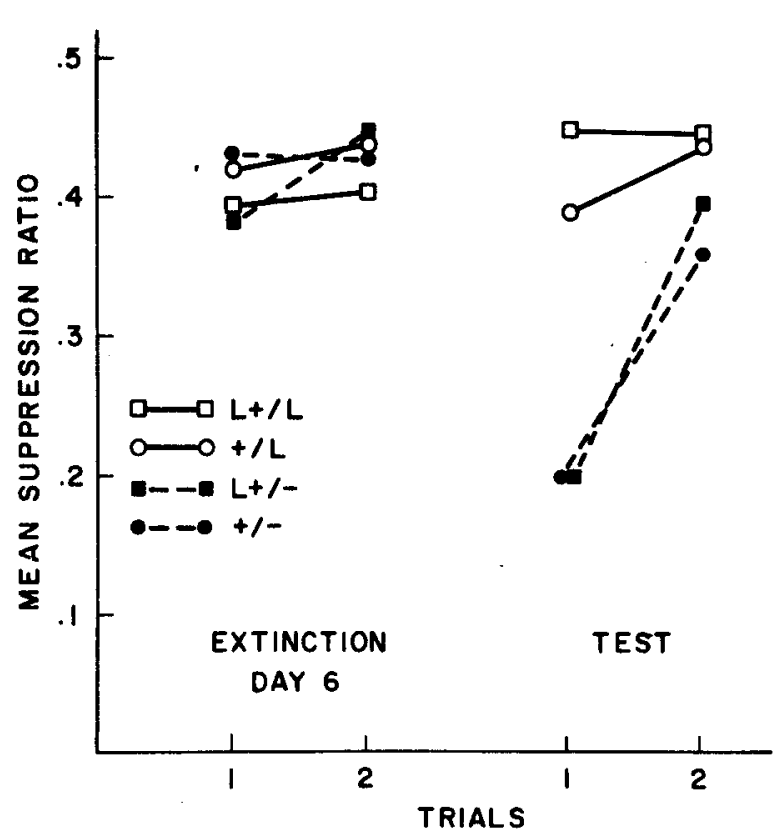

Figure 1. Mean suppression ratio on the final two tone extinction trials and the two test trials of Experiment 1. Prior to the test trials, all groups received reinstating shocks, but differed in whether those shocks were preceded by light $(\mathrm{L}+)$ or not $(+)$ and whether nonreinforced lights $(L)$ intervened or not $(-)$ prior to tone presentation.

erasers were not statistically reliable. In this experiment, those differences in strength of fear produced by the light were purposefully maximized.

Third, this experiment examined whether the similarity of treatment of the light and tone during acquisition and extinction in Experiment 1 was essential to the erasure effect. One might suppose that training and extinguishing the light and tone in parallel fashion within the same session would be critical for erasure. For instance, those procedures insure that, prior to the test session, nonreinforcement of the light always occurred in a context in which the tone was also nonreinforced. For that reason, nonreinforced light presentations during the test session might reinstitute stimulus conditions like those in which the tone was previously nonreinforced, thus reducing the response to the tone. Consequently, the present experiment examined erasure under procedures which separated in time the conditioning treatments of the light and tone.

\section{Method}

Subjects and Apparatus. The subjects were 24 male SpragueDawley rats maintained as in Experiment 1. The apparatus was that of Experiment 1.

Procedure. The rats were barpress trained as in Experiment 1. Thereafter, all sessions were $2 \mathrm{~h}$ long and all involved food reinforcement for barpressing on a VI 2-min schedule. After 5 days of simple VI performance, two pretest sessions were given. During each session, each animal received two nonreinforced $1,800-\mathrm{Hz}$ 
tones and two nonreinforced flashing lights, each 2 min in duration. The next session began a 4-day conditioning sequence, designed to ensure the relative neutrality of the light in one group while making it a fear elicitor in two other groups. Animals in Group $L$ - received four nonreinforced 2 -min presentations of the light on each day. Animals in Groups $\mathrm{L}+$ and $\mathrm{C}+\mathrm{re}-$ ceived four 2-min lights on each of the first 2 days and simple VI training on the next 2 days. In the latter groups, each light terminated in a .5-mA, .5-sec footshock.

On the next 2 days, all animals received fear conditioning with the tone CS. Each day contained four 2-min tones, each terminating in a .5-mA .5-sec footshock. Following conditioning of the tone, 4 days of tone extinction were given. Treatment on these days was identical to that of conditioning days, except that all shocks were omitted. On the next day, all animals received four unsignaled shocks while barpressing, with the intention of reinstating fear to the tone.

Finally, a single test session was administered. During the second hour of this 2-h session, all animals received two 2-min nonreinforced tones. During the first hour, animals in Groups L and $\mathrm{L}+$ received two 2-min nonreinforced lights; animals in Group $\mathrm{C}+$ had no explicitly programmed stimulus events during this time. The result of these treatments is that for Group L + the testing of the tone was preceded by a fear-eliciting light, whereas in Group $\mathbf{L}-$ it was preceded by a neutral light. In Group $\mathrm{C}+$, a light had previously been conditioned but was not presented during the test session.

\section{Results and Discussion}

By the end of initial conditioning of the light, the suppression ratios of Groups $\mathrm{L}+$ and $\mathrm{C}+$ were quite low (a mean of .03), whereas the mean for Group L was substantially higher at .40 . Nevertheless, conditioning of the tone proceeded similarly regardless of the previous treatment of the light. In Group L - , the mean suppression ratios in blocks of two tone acquisition trials were $.47, .36, .09$, and .10 . The means for Groups $\mathrm{C}+$ and $\mathrm{L}+$ combined were .45 , $.37, .07$, and .09 . A comparable pattern occurred in extinction, supporting previous findings in our laboratory of no detectable stimulus generalization between this light and tone.

The results of principal interest, from the final extinction trials and the postreinstatement test session with the tone, are shown in Table 1. As in previous experiments, substantial reinstatement occurred in a group without intervening light presentation (Group $\mathrm{C}+$ ). Moreover, the presentation of the fear-eliciting light in Group $\mathrm{L}+$ attenuated that reinstatement. However, the similar presentation of the neutral light in Group L - produced no evidence of attenuation. Mann-Whitney $U$ tests revealed that Group L + showed less suppression to the tone than did either of the other groups (Us $<14$,

Table 1

Mean Suppression Ratios From Experiment 2

\begin{tabular}{cccc}
\hline & Last Extinction & \multicolumn{2}{c}{ Test Trials } \\
\cline { 3 - 4 } Group & Trials & 1 & 2 \\
\hline L+ & .42 & .33 & .38 \\
L- & .48 & .16 & .30 \\
$\mathrm{C}+$ & .44 & .18 & .34 \\
\hline
\end{tabular}

ps $<.05)$ but that Groups $\mathrm{L}-$ and $\mathrm{C}+$ did not differ. During the test trials, the mean numbers of responses during the pre-CS periods were 22,17 , and 22 for Groups $\mathrm{C}+, \mathrm{L}-$, and $\mathrm{L}+$; these were not reliably different from each other.

Of course, Groups L + and L - also differed substantially in suppression during the test session light presentations, respectively giving mean ratios of .06 and .43 . The similarity of the latter figure to that for Group L - at the end of light conditioning agrees with earlier findings that unsignaled shocks do not "reinstate" fear to neutral stimuli in this procedure (Rescorla \& Heth, 1975).

Thus, these results replicate the erasing effect of intervening light presentations found in Experiment 1. More importantly, they indicate that this effect is related to the light's fear-eliciting power; the neutral light in Group L - produced no erasure. This pattern is consistent with the view that reinstatement and erasure affect the US representation independently of any particular CS.

\section{EXPERIMENT 3}

This experiment had two purposes. First, it sought to provide evidence on the completeness of the erasure effect. The previous experiments have suggested that erasure is substantial but they did not contain a nonreinstated group essential for deciding whether erasure can completely reverse the effects of a reinstating shock. This experiment contained such a group and additionally increased the number of presentations of the eraser so as to maximize its effect.

Second, this experiment attempted to use the erasure effect to study the interaction of associative and nonassociative changes during extinction. The present interpretation has described nonreinforced CS presentation as having deliterious effects upon both the associative connections and the US representation. Furthermore, we have assumed that these two types of change interact in generating performance. The question of Experiment 3 was whether they also interact in generating learned changes. The results of Experiment 2 illustrate one form of such an interaction by showing that stimuli with associative connections to a US representation are especially potent in changing that representation when they are nonreinforced. That is, the status of the associative connections to a CS affects the degree to which its nonreinforcement changes the US representation. Experiment 3 examined the converse interaction by asking whether the status of the US representation affects the associative consequences of nonreinforcing that $\mathrm{CS}$.

The intention of the experiment was to nonreinforce repeatedly a previously conditioned stimulus in groups which differed in the state of their US 
representation at the time of that nonreinforcement. To this end, three groups were initially fear conditioned and partially extinguished with a tone CS; all groups then received additional extinction trials with the tone. For one group, those extinction trials occurred on alternate days with reinstating shocks on the other days. For that group, then, nonreinforced tone trials occurred in the presence of a US representation made strong by reinstatement. For one comparison group, nonreinforced tones occurred without intervening reinstatement (i.e., a continuation of the standard extinction procedure). For a second comparison group, reinstatements were given on alternate days, but erasing presentations of a second exciter preceded tone extinction trials. Those latter two groups thus received their tone extinction trials at a time when the US representation was low, either because of failure to reinstate or because of erased reinstatement. The particular advantage of the erased group is that it shares with the simple reinstatement group many of the general consequences of shock presentation, but it uses erasure specifically to depress the US representation just prior to nonreinforcement of the tone. The differential effectiveness of these treatments in attenuating the association was assessed in a final tone-reconditioning procedure. The issue of interest is whether reconditioning will proceed at different rates depending upon the state of the US representation during the previous nonreinforced tone trials.

\section{Method}

Subjects and Apparatus. The subjects were 32 male SpragueDawley rats maintained as in the previous experiments. The apparatus was that of Experiments 1 and 2.

Procedure. After initial barpress training, all sessions were $2 \mathrm{~h}$ long and involved food reinforcement on a VI schedule. Pretesting was given as in Experiment 1; then all animals received fear conditioning with both the $1,800-\mathrm{Hz}$ tone and the flashing houselight. On each of five conditioning days, each stimulus was presented twice for $2 \mathrm{~min}$ and terminated in a $.5-\mathrm{mA}, .5-\mathrm{sec}$ footshock. On the following 2 days, the fear of the tone was extinguished. On each extinction day, all animals received four nonreinforced presentations of the 2 -min tone. By the end of this extinction, seven animals were found to be substantially more fearful than the others; their highest suppression ratio was .13, while the lowest of the remaining 25 animals was .30 . In order to reduce pretreatment variability within groups, those seven animals were discarded and the remaining animals assigned to three groups of 8,8 , and 9 animals each.

The next day began the first of four treatment cycles, each of which consisted of a 2-day reinstatement and test sequence. On the first day of each cycle, the animals in Group $\mathrm{L}+/ \mathrm{L}-$ $(n=9)$ and Group $L+1$ - each received four 2 -min light presentations, each of which terminated in a .5-mA, .5-sec footshock. Animals in Group C (control) received no programmed events but continued performance on the VI schedule of food reinforcement on this day. On the second day of each cycle, all animals received two nonreinforced presentations of the 2-min tone during the final third of the 2 -h session. For animals in Groups $C$ and $L+/-$, the first part of that session contained no programmed stimulus events; for those in Group $L+/ L-$, it contained four nonreinforced presentations of the 2-min light.
The intention of these treatments was to use reinstatement (i.e., $\mathbf{L}+$ ) to ensure a strong US representation, and thus substantial fear, during the tone presentations for Group $\mathrm{L}+/-$, while guaranteeing less fear in the other groups, either by failing to reinstate (Group C) or erasing that reinstatement (Group $\mathrm{L}+/ \mathrm{L}-$ ).

On the next 2 days, a final cycle was administered. This cycle differed from the preceding four in two ways. First, all groups were treated like $\mathrm{L}+/-$, receiving both reinstating light-shock pairings and no erasure. The intention was to assess the effectiveness of the different extinction treatments under comparable conditions of final reinstatement. Second, the final tone presentation of this cycle terminated in a .5-mA, .5-sec footshock. This shock was intended to begin reconditioning of fear to the tone. The next day contained a single reconditioning session on which all animals receiving four presentations of the tone, two of which were followed by shock. The data of this session provide a savings test relevant to the success of the various extinction procedures in reducing the associative learning controlled by the tone.

\section{Results and Discussion}

Figure 2 summarizes the major results of the tone presentation in the various stages of this experiment. Performance on the final two extinction trials was comparable among the groups. However, the first cycle of reinstatement and testing confirmed the results of Experiments 1 and 2 in producing differential suppression as a function of reinstatement and erasure. On that first test session, Group $\mathrm{L}+1-$ showed a substantial increase in suppression whereas neither the nonreinstated control group $(\mathrm{C})$ nor the erasure group $(\mathrm{L}+/ \mathrm{L}-)$ showed evidence of suppression. As in previous experiments, that reinstatement was largest on the first test trial, on which

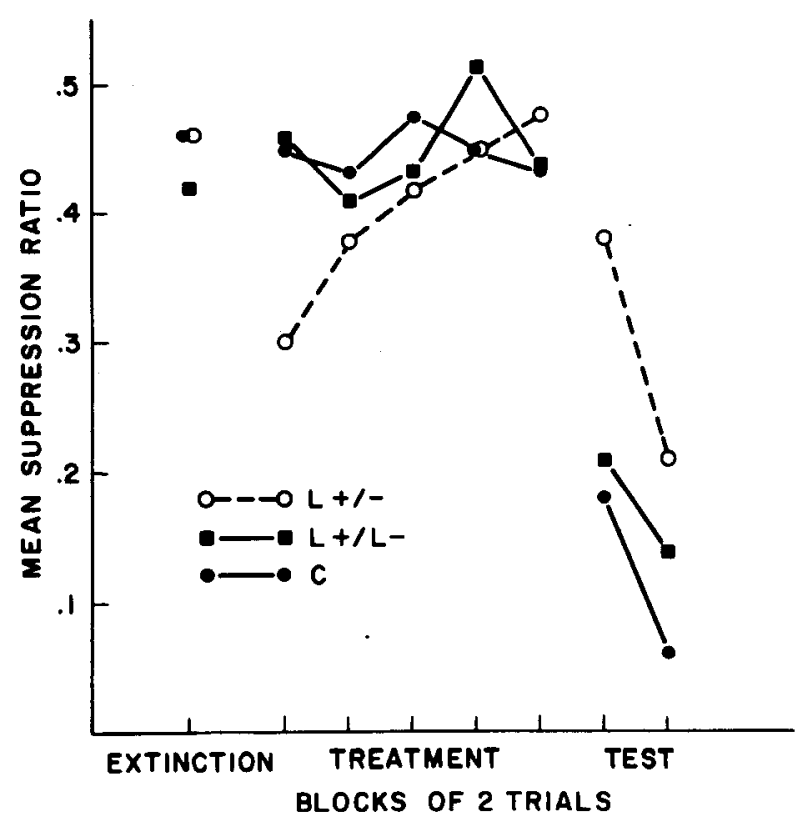

Figure 2. Mean suppression ratios at the end of tone extinction, during the course of differential treatment, and during reinforced test presentations of the tone in Experiment 3. During treatment, Groups $\mathbf{L}+/-$ and $\mathbf{L}+/ \mathbf{L}-$ received reinstating shocks, (i.e., $\mathbf{L}+$ ) but Group $\mathbf{C}$ did not. Group $\mathbf{L}+/ \mathbf{L}-$ additionally received nonreinforced lights during that phase. 
Groups $\mathrm{L}+/-, \mathrm{C}$, and $\mathrm{L}+/ \mathrm{L}-$ showed suppression ratios of $.13, .46$, and .42 , respectively. On that trial, Group L $+/-$ differed reliably from each of the other groups (Mann-Whitney $U_{s}=1,5$, ps $<.01)$ whereas the control and erasure groups were not statistically different. The pre-CS rates for that trial were 15,15 , and 19 , which were not reliably different from one another. Thus the results of the initial cycle display both reinstatement and its erasure, as well as suggesting that erasure can completely reverse reinstatement.

With repeated administration of reinstatement and test, the three groups converged, indicating a reduction in the ability of intervening light shock pairings to reinstate. Presumably this change partly reflects a reduction in the associative strength resulting from additional extinction. On the final cycle, when all groups received comparable treatment, there was a small but nonreliable reinstatement in Groups $\mathrm{L}+1$ $\mathrm{L}-$ and $\mathrm{C}$. During the first trial of that session, however, Group L + $/ \mathrm{L}-$ did show greater suppression than did Group $L+/-(U=13, p<.05)$; the ratios were .32 and .43 , respectively. The .41 ratio shown by Group $\mathrm{C}$ was not reliably different from either of those ratios. Thus the final reinstatement cycle showed only marginal evidence that the treatments had resulted in differential associative changes.

Much stronger evidence for differential associative change is shown in the reconditioning savings test, displayed to the right of Figure 2. In that test, Groups $\mathrm{L}+/ \mathrm{L}-$ and $\mathrm{C}$ both showed substantially more suppression to the tone than did Group $\mathrm{L}+/-$. Over that day, both differences were reliable (Us = $17.5,6$, respectively), whereas the erasure and control groups did not differ reliably. As in previous phases of the experiment, group differences were strongest on the initial trial of this session (a trial which had been preceded by a single reconditioning trial at the end of the final cycle). On that trial, Groups $\mathrm{L}+/-, \mathrm{L}+/ \mathrm{L}-$, and $\mathrm{C}$ gave ratios of .37 , .18 , and .03 respectively. Each pairwise comparison proved reliable (Us $<11$, ps $<.02$ ).

These results suggest that the nonreinforcement of the tone CS had differential effects upon its association depending upon the current state of the US representation. Nonreinforcement in the presence of a strong representation in Group $\mathrm{L}+/-$ especially depressed the association, as indexed by its retarded subsequent reacquisition. Two techniques for reducing that representation both resulted in less associative loss when the tone was nonreinforced.

The comparison of Group $\mathrm{L}+1$ - with that of Group C yields results similar to those of several investigators who have employed unpaired US delivery during extinction of Pavlovian conditioning. That treatment often retards extinction and may also slow subsequent reconditioning (e.g., Frey \& Butler, 1977; Spence, 1966). The present reinstatement procedure enjoys an advantage over such extinction procedures, however, by imposing an extended time interval between the presentation of the US and the test presentation of the extinguished CS. By doing so, this procedure more successfully avoids interpretation in terms of the immediate effects of US presentation, acting either as a stimulus which was also present in conditioning or as a source of unconditioned drive or arousal.

Nevertheless, the comparison of Group $\mathrm{L}+1-$ and Group $C$ shares with the comparison between simple extinction and extinction with continued US presentation the complications introduced by any general debilitating effects of repeated US presentation. In both comparisons, repeated US presentation might induce different reinforcing power for the US at the time of reconditioning and generate different rates of relearning in that fashion. For this reason, the comparison of Group $\mathrm{L}+/-$ with Group $\mathrm{L}+/ \mathrm{L}$ - may provide more precise information on the interaction of associative and US representational changes in extinction. Those groups share a similar history of overall shock presentation but differ specifically in the state of the US representation during nonreinforced tone presentations. In this context, it is worth noting that one interpretation of the difference in initial reacquisition between Group L $+/ \mathrm{L}-$ and Group $\mathrm{C}$ is that they differ in sensitivity to the current shock as a result of their different histories of shock presentation.

\section{GENERAL DISCUSSION}

The results of these experiments support the proposition that there are learned changes which occur in extinction which are not well described as modifications of the associations controlled by the extinguishing $\mathrm{CS}$. They suggest that a representation of the US can be depressed, reinstated, and redepressed by manipulations which do not involve treatment of the target CS but which do affect the performance it can provoke. The language of the present interpretation has described that representation as nonassociative; but before developing that position further, we should comment on two competitive associative interpretations of the results reported here and in the previous paper.

One possibility is that although our manipulations do leave unaffected the association between the CS and US, they simultaneously modify a facilitative association between background stimuli and the US. One version of this hypothesis would ascribe reinstatement to the simple summation of the fear controlled by the CS and that elicited by the background. Alternatively, such background condi- 
tioning might have a more indirect facilitative effect upon the response elicited by the CS. For instance, both Konorski (1967) and Spence (1956) have argued that US presentations might condition drive to background stimuli, thus allowing them to amplify the consequences of CS presentation.

There is little doubt that under some circumstances the separate presentation of a US can result in the conditioning of background stimuli (e.g., McAllister $\&$ McAllister, 1962). Indeed, some theories of Pavlovian conditioning make heavy use of the associative consequences of such presentation in providing accounts of the role of CS/US contingencies in conditioning (e.g., Rescorla \& Wagner, 1972). The present issue is whether background stimulus conditioning of this sort can comfortably account for reinstatement and its erasure.

There are several lines of evidence which, taken together, make background stimulus conditioning seem a poor account of these phenomena. The first type of evidence has to do with the failure to observe other evidence of substantial background conditioning following the reinstating manipulations used here. Throughout these studies, we have repeatedly failed to see reliable suppression of pre-CS response rates as a result of reinstatement. The results of the first test cycle from Experiment 3 above illustrate that point. Although such base-rate changes are perhaps not a particularly sensitive index of background conditioning, they are readily observed in other contexts to which such an account has been applied (e.g., Dweck \& Wagner, 1970). The failure to see base-rate changes with such substantial reinstatement is, of course, particularly damaging to an account of reinstatement in terms of summation of $\mathrm{CS}$ and background fear.

The second kind of evidence against an important role of background stimulus conditioning comes from the insensitivity of reinstatement to manipulations which would be expected to produce marked changes in that conditioning. In the previous report, Rescorla and Heth (1975) examined reinstatement resulting from shocks which were either unsignaled, signaled by other excitatory stimuli, or signaled by neutral stimuli. Such manipulations are known to have important blocking and overshadowing consequences for experimentally manipulated stimuli, but they had no detectable effect upon the magnitude of reinstatement. Experiment 1 of the present report contains further evidence of this sort. Similarly, various studies in the present report have given substantial exposure to background stimuli during the test session prior to presentation of the CS; but such extensive opportunity for the background stimuli to extinguish apparently did not disrupt reinstatement.

Finally, in spite of the failure of extended presen- tation of background stimuli to "extinguish" reinstatement, a few nonreinforced presentations of a known fear elicitor markedly erased it. It is not clear that an interpretation in terms of background stimulus conditioning can make that discrepancy understandable. These arguments suggest that interpreting reinstatement simply as a case of standard Pavlovian conditioning of background stimuli is implausible. They do not, of course, imply that reinstatement is free of the situation in which it is carried out. The subject may learn the features of a US which occurs in a particular experimental situation, but the present data suggest that the rules governing that learning and its removal may differ markedly from those derived from studies of experimenterpresented CSs.

A second associative account of reinstatement and erasure appeals to changes in the conditioning not of background stimuli but of other experimentercontrolled CSs. The fact that many of the operations intended to manipulate the US representation entail reinforcement and extinction of other CSs suggests the possibility that changes in those CSs show stimulus generalization to the target stimulus. For the stimuli employed in the present studies, this possibility does not seem particularly plausible. These stimuli are ones which are frequently used in this laboratory and have been selected because of their repeated failure to show stimulus generalization to each other. One example of that failure can be seen in the acquisition data from Experiment 2. In that study, prior conditioning with the light had no detectable effect upon subsequent conditioning with the tone. Similarly, the failure to find differences in magnitude of reinstatement to the tone as a function of whether or not the shocks were signaled by the light, both in previous studies and in the present Experiment 1, seems inconsistent with an interpretation in terms of stimulus generalization.

Finally, in Experiment 3 the effect of erasure by nonreinforced presentations of the light (Group $\mathrm{L}+/ \mathrm{L}-$ ) was to better preserve the associative strength of the tone. Yet, if erasure simply involved stimulus generalization of extinction, that outcome would not be anticipated.

It is important to note that these arguments are not meant to imply that there is no transfer between the light and the tone in the sense that treatments with one would necessarily leave the other unaffected. The present argument is only that such transfer is not the result of stimulus generalization of associations but, rather, is mediated by a shared US representation which is independent of those associations.

If one accepts the role of a nonassociative learning process in generating reinstatement and erasure, then we may use those phenomena to help construct a description of the associative and nonassociative 
changes which occur in standard Pavlovian conditioning and extinction paradigms. The occurrence of reinstatement suggests that a very few presentations of a US, regardless of the events signaling its occurrence, can greatly strengthen the US representation. Thus, in a simple A-US conditioning procedure, the US representation is rapidly augmented at the same time as the association is formed. The present data do not provide detailed information about the interaction of these kinds of learning during acquisition. But the fact that one-trial conditioning can be observed in such settings (e.g., Kremer, 1971; Mahoney \& Ayres, 1976) suggests that the formation of the US representation need not precede associative learning.

Likewise, the phenomenon of erasure suggests that a few occurrences of a stimulus previously associated with a US can markedly depress the representation of that US. Thus on initial extinction trials, one may expect both rapid depression of that representation and some associative changes. Moreover, the results of Experiments 2 and 3 suggest an interaction between these changes in extinction. The stronger the association, the greater the reduction in the US representation (Experiment 2), and the stronger the US representation, the greater the decrement in associations (Experiment 3 ).

There are several theoretical frameworks within which to view these interactions. One possibility would be to follow Konorski (1967) and Spence (1956) in giving the US representation drive properties which facilitate performance and perhaps modulate learning. Although those theorists tied such drive properties to the conditioning of situational cues or the immediate aftereffects of US presentation, that tie is not mandatory. An alternative theoretical framework was originally suggested by Konorski (1948) and adapted by Grice (1972) and Rescorla (1974). These authors suggested that the mapping of associations into performance is modulated by a threshold which is itself subject to change. One determinant of that threshold suggested by Konorski is the "excitability of the US center," which may be roughly translated into the US representation. On such a view, a strong US representation sets a low threshold for the exhibition of associative strength of CSs associated with that US; weak representations return the threshold toward a higher resting state.

One may further presume that changes in associative strength and in the state of the US representation depend upon that performance. For instance, as suggested by Zimmer-Hart and Rescorla (1974) in another context, the equations used by Rescorla and Wagner (1972) to describe associative learning could acknowledge the importance of a threshold in modifying the associative strength. Moreover, using data like those reported here, one could envision comparable rules to describe the changes in the US representation, and therefore the threshold. Such rules would have to acknowledge the role of simple US presentation in building up that representation as well as the role of the nonreinforcement of CSs which arouse that representation in producing its destruction.

Such a framework might also provide a common language in which to talk about a range of factors other than associative strength which affect learning and performance. For instance, motivational variables might affect the threshold in studies where the value of the US depends upon a deprivation state. Then one would anticipate not only lower performance but also less extinction from nonreinforced presentation of a CS under low drive (see Holland \& Rescorla, 1975). Similarly, Zimmer-Hart and Rescorla (1974) have suggested that conditioned inhibition might have its primary effect through changing a threshold of this sort; its presence, too, would then be expected to reduce the decremental effects of nonreinforcement (see Chorazyna, 1962).

Whatever the value of such speculations, it is clear from the present data that nonassociative changes contribute heavily to performance during extinction. Moreover, those changes seem to be extremely rapid so as to give to performance a liability perhaps greater than that attributable to associations. Finally, the present experiments make some initial steps toward suggesting the rules governing those nonassociative changes.

\section{REFERENCES}

Chorazyna. H. Some properties of conditioned inhibition. Acta Biologiae Experimentalis, 1962, 22, 5-13.

Dweck, C. S., \& WAGNer, A. R. Situational cues and cor relation between CS and US as determinants of the conditioned emotional response. Psychonomic Science, 1970, 18, 145-147.

Frey, P. W., \& Butler, C. S. Extinction after aversive conditioning: An associative or nonassociative process? Learning \& Motivation, 1977, 8, 1-17.

GRICE. G. R. Conditioning and a decision theory of response evocation. In G. H. Bower (Ed.). The psychology of learning and motivation: Advances in research and theory (Vol. 5). New York: Academic Press, 1972.

Holland. P. C.. \& Rescorla, R. A. The effect of two ways of devaluing the unconditioned stimulus after first- and secondorder appetitive conditioning. Joumal of Experimental Psychology: Animal Behavior Processes, 1975, 1, 355-363.

KONORSKI. J. Conditioned reflexes and neuron organization. New York: Cambridge University Press, 1948.

KonorSKI. J. Integrative activity of the brain. Chicago: University of Chicago Press, 1967.

KREMER. E. F. Truly random and traditional control procedures in CER conditioning in the rat. Journal of Comparative and Physiological Psychology, 1971, 76, 441-448.

Mahoney, W. J., \& AYres, J. J. B. One-trial simultaneous and backward fear conditioning as reflected in conditioned suppression of licking in rats. Animal Learning \& Behavior, 1976. 4. 357-362 
McAllister, W. R., \& McAllister, D. E. Role of the CS and of apparatus cues in the measurement of acquired fear. Psychological Reports, 1962, 11, 749-756.

Rescorla, R. A. A model of Pavlovian conditioning. In V. S. Rusinov (Ed.), Mechanisms of formation and inhibition of conditional reflex. Moscow: Academy of Sciences of the U.S.S.R., 1974.

Rescorla, R. A., \& Heth. C. D. Reinstatement of fear to an extinguished conditioned stimulus. Journal of Experimental Psychology: Animal Behavior Processes, 1975, 104, 88-96.

Rescorla, R. A., \& Wagner, A. R. A theory of Pavlovian conditioning: Variations in the effectiveness of reinforcement and nonreinforcement. In A. H. Black \& W. F. Prokasy (Eds.). Classical conditioning II: Current theory and research.
New York: Appleton-Century-Crofts, 1972.

SPENCE, K. W. Behavior theory and conditioning. New Haven: Yale University Press. 1956.

Spence, K. W. Extinction of the human eyelid $C R$ as a function of the presence or absence of the UCS during extinction. Joumal of Experimental Psychology, 1966. 71. 642-648.

Zimmer-Hart, C. L., \& Rescorla, R. A. Extinction of Pavlovian conditioned inhibition. Joumal of Comparative and Physiological Psichology, 1974, 86, 837-845.

(Received for publication February 25, 1977; revision accepted June 3.1977 .) 